\title{
IMPLEMENTAÇÃO DE AÇÕES REALIZADAS CONCOMITANTES AO \\ PROTOCOLO DE QUEDAS PARA REDUZIR OS EVENTOS ADVERSOS
}

BARBOSA, Adriana Santos; SOUZA, Viviane Dias de; DANTAS, Mainara Honorato; VITIELLO, Queli Cristina Cruz; GASPARINI JUNIOR, José Luiz

\section{INTRODUÇÃO E OBJETIVO}

Queda é citada como fator de risco funcional da capacidade nos indivíduos hospitalizados. Apresenta incidência que varia de 1,1 a $22 \%$.

A análise desse tema é mundialmente abordado nas instituições, e periodicamente revisitado, a fim de criar barreiras preventivas. O reconhecimento e a avaliação dos fatores de risco são cruciais no planejamento do processo de prevenção.

Dentro deste cenário, esse projeto piloto teve como objetivo diminuir $20 \%$ a taxa de queda dos pacientes por meio, de análise das possíveis causas na instituição.

\section{MATERIAL E MÉTODOS}

- Escolha de uma unidade para realização do piloto;

- Discussão das principais causas do aumento com a equipe assistencial (brainstorming);

- Treinamento $100 \%$ para equipe da unidade piloto;

- Aplicação de antideslizante nos pisos dos banheiros dos quartos;

- Teste de novo modelo de suporte de soro;

- Placas de sinalização no quarto identificando por cor o grau do risco de queda;

- Orientação do risco de queda ao paciente/ familiares a cada plantão;

- Painel no posto de enfermagem informando à unidade a quantidades de dias que não há o evento queda;

- Auditoria dos pacientes elegíveis ao risco verificando se a triagem foi realizada corretamente.

\section{RESULTADOS E DISCUSSÃO}

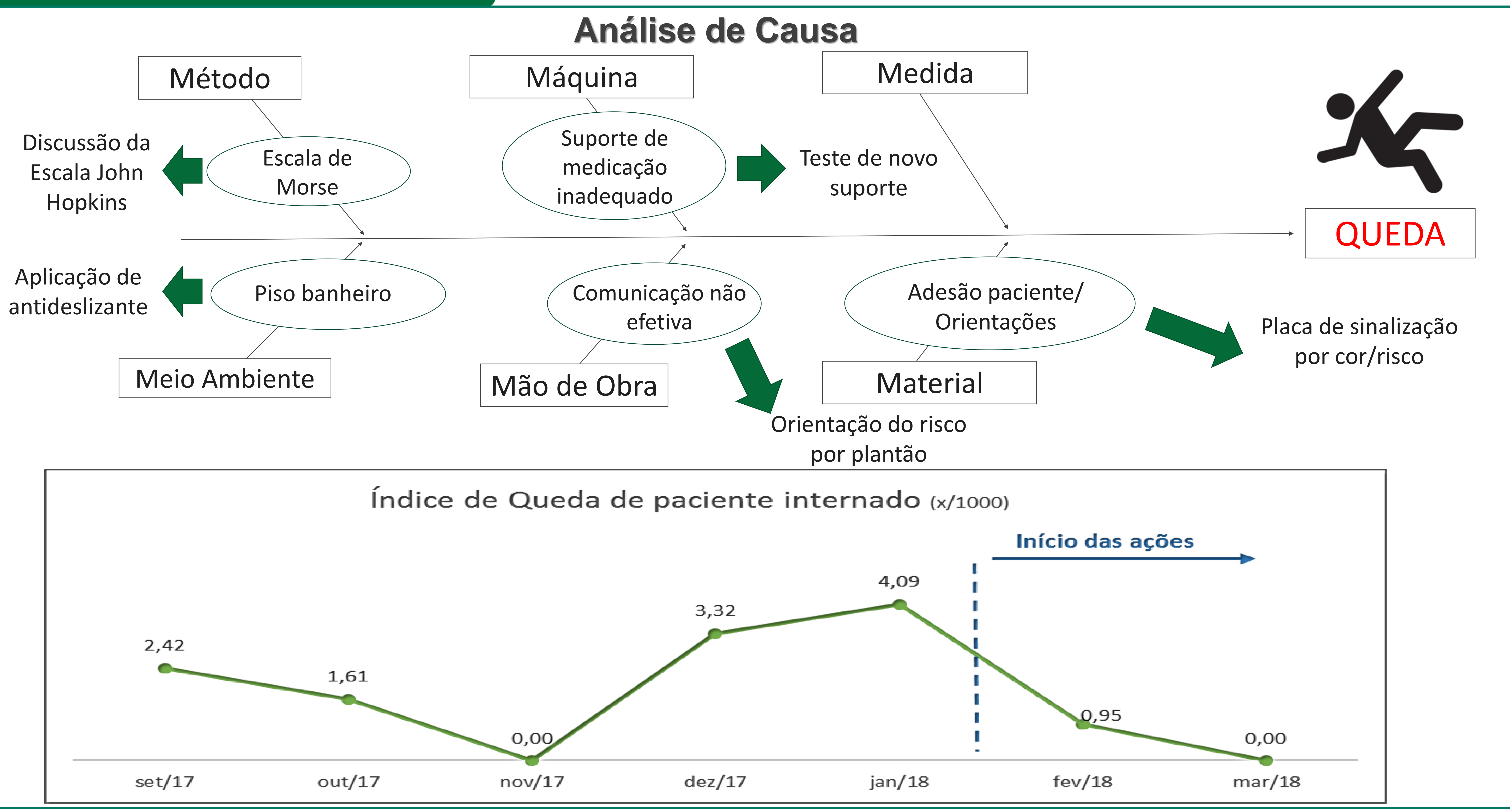

\section{CONCLUSÃO}

Esse projeto demonstrou a importância e o benefício de revisitar as fragilidades e determinar novas medidas preventivas no protocolo de risco para queda, além de intensificar a adesão e o engajamento das equipes para eficácia do protocolo. Este processo resulta em diminuição do tempo de hospitalização, custos hospitalares, e exposição dos pacientes a possíveis danos transitórios/permanentes ou até mesmo fatais. 